\title{
Examining changes in maternal and child health inequalities in Ethiopia
}

\author{
Alemayehu A. Ambel ${ }^{1 *}$ (D), Colin Andrews ${ }^{1}$, Anne M. Bakilana², Elizabeth M. Foster ${ }^{1}$, Qaiser Khan ${ }^{1}$ and Huihui Wang
}

\begin{abstract}
Background: Ethiopia has made considerable progress in maternal, newborn, and child health in terms of health outcomes and health services coverage. This study examined how different groups have fared in the process. It also looked at possible factors behind the inequalities.

Methods: The study examined 11 maternal and child health outcomes and services: stunting, underweight, wasting, neonatal mortality, infant mortality, under-5 mortality, measles vaccination, full immunization, modern contraceptive use by currently married women, antenatal care visits, and skilled birth attendance. It explored trends in inequalities by household wealth status based on Demographic and Health Surveys conducted in 2000, 2005, 2011, and 2014. The study also investigated the dynamics of inequality, using concentration curves for different years. Decomposition analysis was used to identify the role of proximate determinants.
\end{abstract}

Results: The study found substantial improvements in health outcomes and health services: Although there is still a considerable gap between the rich and the poor, inequalities in health services have been reduced. However, child nutrition outcomes have mainly improved for the rich. The changes observed in wealth-related inequality tend to reflect the changing direct effect of household wealth on child health and health service use.

Conclusions: The country's efforts to improve access to health services have shown some positive results, but attention should now turn to service quality and to identifying multisectoral interventions that can change outcomes for the poorest.

Keywords: Maternal and child health, Health inequalities, Health care utilization

\section{Background}

Improving maternal and child health was integral to the Millennium Development Goals (MDGs) for 1990-2015: Goal 4 called for a two-thirds reduction in under-5 mortality, and Goal 5 for a $75 \%$ reduction in maternal mortality. The goals received global attention as countries and their international development partners mobilized support to, e.g., expand childhood immunization and increase the availability and utilization of maternal health services.

Ethiopia made considerable progress towards achieving the targets. In 2011 the Center for Global Development reported satisfactory progress on all goals and ranked Ethiopia 33rd of 137 countries, with an MDG progress index of 4.5 on a scale of zero to 8 points [1].

\footnotetext{
* Correspondence: aambel@worldbank.org

${ }^{1}$ The World Bank, 1818 H Street, Washington, DC 20046, USA

Full list of author information is available at the end of the article
}

According to a 2012 UN report, all the MDG targets in Ethiopia were either on track or likely to be on track [2].

The 2014 mini-Demographic and Health Survey (DHS) found reductions in child undernutrition and child mortality and increased coverage of maternal, newborn, and child health $(\mathrm{MNCH})$ services like antenatal care, contraceptive prevalence, and skilled birth attendance (SBA) [3]. With the MDG period behind us and new targets set in the Sustainable Development Goals (SDGs), attention is now turning to whether the achievements recorded were inclusive [4]. Of the few studies on health inequalities in Ethiopia, most analyzed just one or two indicators at the national level [5-8], while others examined one or two indicators for a specific region or city $[6,9]$.

In this study, we provide evidence of the dynamics of $\mathrm{MNCH}$ inequalities. The study contributes to the empirical evidence by adding a more detailed inequality analysis using data from a series of comparable recent surveys. 
The surveys allow us to analyze the changes in inequalities over a period that overlaps with most of the MDG period. We also examine the contribution of socioeconomic determinants of maternal and child health outcomes.

\section{Methods}

\section{Indicators and definitions}

Table 1 presents the six health status and five health service indicators analyzed in this study, chosen based on their relevance to the health MDGs and on the availability of data. For health status, there are three child undernutrition and three mortality indicators: stunting, wasting, underweight, neonatal mortality rate (NMR), infant mortality rate (IMR), and under-5 mortality rate (U5MR). The service indicators cover child immunization and maternal health services; they are measles vaccination, full immunization, prevalence of modern contraceptive use by married women, four or more antenatal care visits from a skilled professional (ANC4+), and delivery assistance from a skilled birth attendant (SBA). Additional file 1: Table 1a and $b$ present details of the indicators and terms as used in the analysis.

\section{Data sources and variable construction}

The data are from four Ethiopia Demographic and Health Surveys (DHSs), in 2000, 2005, 2011, and 2014. These population-based surveys target mainly women of childbearing age (15 to 49 ) but also collect some data about the household and some from men in the same age range. The main survey concerns are fertility, family planning, infant and child mortality, maternal and child health, and nutrition. Since 2000, they have been conducted about every 5 years. The first three surveys each sampled about 15,000 women from about the same number of households. The sample for the 2014 survey was about half that of the previous rounds. Much of the data used in this study comes from the women's questionnaire, which compiles a comprehensive birth history for each woman, from antenatal care and delivery attendance through child survival and vaccination. The questionnaires used in the different surveys are standard and comparable. The data provide nationally representative information on the variables we selected for this study.

The primary qualifying variable is wealth ranking. We looked at socioeconomic inequalities in health by wealth ranking between the worse-off (bottom $40 \%$ ) and the better-off (top 60\%) and between the poorest (1st quintile) and the richest (5th quintile). These are computed from the household wealth index available with the data [10].

To evaluate child undernutrition, we computed anthropometric indicators based on the WHO 2006 growth standards: We calculated height-for-age, height-forweight, and weight-for-age z-scores and then stunting, wasting, and underweight levels for children aged 0 to 59 months. Child mortality rates (IMR, NMR, and U5MR) are calculated using the standard DHS methodology, using data on all child deaths in the 5-year period preceding each survey [8]. We calculated the prevalence of modern contraception use by currently married women, antenatal care (most recent birth), and skilled birth attendance (all births in last 5 years) from the questionnaire administered to all women aged 15-49 years in the household.

\section{Data analysis}

For a more complete picture, we considered a combination of the approaches often used in inequality studies because each approach has some limitations that can lead to different conclusions $[11,12]$. Our analysis started with

Table 1 Maternal and child health indicators analyzed in this study

\begin{tabular}{|c|c|}
\hline Indicators & Definition \\
\hline Stunting & Percentage of children with a height-for-age $z$-score $<-2$ standard deviations from the reference median \\
\hline Wasting & Percentage of children with a weight-for-height $z$-score $<-2$ standard deviations from the reference median \\
\hline Underweight & Percentage of children with a weight-for-age $z$-score $<-2$ standard deviations from the reference median \\
\hline Neonatal mortality rate (NMR) & The number of neonates dying before reaching 28 days of age per 1000 live births \\
\hline Infant mortality rate (IMR) & The number of deaths among children under 12 months of age per 1000 live births \\
\hline $\begin{array}{l}\text { Under-5 mortality rate } \\
\text { (U5MR) }\end{array}$ & The number of deaths among children under 5 years of age per 1000 live births \\
\hline Measles vaccination & Percentage of children aged 12 to 23 months who received measles ${ }^{a}$, \\
\hline Full immunization & Percentage of children aged 12 to 23 months who received BCG, measles, and three doses of polio and DPT ${ }^{\mathrm{b}}$, \\
\hline $\begin{array}{l}\text { Contraceptive prevalence } \\
\text { (modern method) }\end{array}$ & Percentage of currently married women aged 15 to 49 who currently use a modern method of contraception \\
\hline $\begin{array}{l}\text { Antenatal care visits, } 4 \\
\text { or more (ANC4+) }\end{array}$ & $\begin{array}{l}\text { Percentage of mothers aged } 15 \text { to } 49 \text { who had a live birth in the past } 5 \text { years who received at least } 4 \text { antenatal } \\
\text { care visits from any skilled personnel during pregnancy for the most recent birth }\end{array}$ \\
\hline Skilled birth attendant (SBA) & $\begin{array}{l}\text { Percentage of live births to mothers aged } 15 \text { to } 49 \text { in the past five years that were attended by skilled health } \\
\text { attendant }\end{array}$ \\
\hline
\end{tabular}


how absolute and relative inequalities between the poor and the rich have widened or narrowed over time. Then, we looked at the concentration curve and concentration index, which capture inequality across a continuous spectrum of wealth, and what they reveal about the changing pattern of inequality over time. Finally, we looked at the decomposition of the concentration indexes to see the changing role of various demographic and socioeconomic factors in the observed wealth-based inequality in health services and outcomes.

We computed absolute inequalities from rate differences between the poor and the rich, defined both as the bottom $40 \%$ versus the top $60 \%$ and as the poorest quintile versus the richest.

The difference-in-differences comparison is as follows: Let $I_{x t}$ be the value of the indicator for group $x$ (either $\mathrm{r}=$ rich or $\mathrm{p}=$ poor) in time period $\mathrm{t}$ (either $t=0$ first survey or $\mathrm{t}=\mathrm{T}$ latest survey). We perform an F-test of the hypothesis:

$$
I_{p 0}-I_{r 0}=I_{p T}-I_{r T}
$$

Second, instead of the difference between the value of the indicator for rich and poor, the ratio of the values was used. This emphasizes the difference between indicators where both groups have very low values. The hypothesis tested was:

$$
\frac{I_{p 0}}{I_{r 0}}=\frac{I_{p T}}{I_{r T}}
$$

The analysis of inequality based on absolute and relative gaps was limited to binary distinctions: rich vs. poor. It was thus somewhat sensitive to the definition of the binary distinction and also did not allow for analysis of inequality across the whole range of wealth outcomes. For example, the comparison of the bottom quintile to top quintile entirely ignored any changes in the health indicator for the middle three-fifths of the population. If we see a decrease in inequality between the bottom $40 \%$ and the top $60 \%$, we do not know whether this was due to improvements for the poorest of the poor or for those closer to the middle of the income distribution. Therefore, we used concentration curves to illustrate the movement of wealth inequalities in health across the entire range of wealth between the earliest and latest surveys. We also used concentration indices $(C)$, which quantify the degree of inequality in this analysis, and observed how they changed between the earliest and latest surveys [13].

A concentration curve plots the inequality of an outcome variable against another factor, here household wealth. It is constructed like a Lorenz curve, which illustrates the degree of inequality in a certain variable such as income. The population is sorted according to wealth, and the cumulative percentage of the indicator ( $y$-axis) is plotted against the cumulative percentage of the population (x-axis). Thus if the bottom $5 \%$ of children by household wealth account for only $1 \%$ of the measles vaccinations, the first point on the curve is $(0.05,0.01)$. Continuing: if the bottom $10 \%$ of children (cumulatively) account for $3 \%$ of measles vaccinations, the second point is $(0.1,0.03)$, and construction of the curve continues in the same way. The concentration curve is often plotted against the 45-degree line, the line of equality the concentration curve would follow if health outcomes were evenly distributed across the wealth rankings.

We would expect the concentration curve for positive health indicators (immunization, maternal health services) to lie below the line of equity (poorer households account for a disproportionately low number of fully vaccinated children or attended births). This is shown in the measles examples above, where both points plotted lie below the 45-degree line. Conversely, we would expect the concentration curve for a negative health indicator (child mortality, malnutrition) to lie above the line of equality (poorer households account for a disproportionately high number of child deaths). We expect that the bottom $5 \%$ of children, ranked by wealth, account for more than $5 \%$ of underweight children and thus the point is above the 45-degree line. A concentration curve that moves closer to the line of equality over time indicates decreasing inequality.

The concentration curve does more than offer a nice visual summary of wealth-based inequality in an indicator; it is also useful to quantify the degree of inequality revealed. The concentration index $(C)$ quantifies the degree of inequality-twice the area between the concentration curve and the line of equality-which is analogous to how the Gini coefficient quantifies the degree of inequality in a Lorenz curve. We calculated $\mathrm{C}$, for each indicator as follows:

$$
C=\frac{2}{\mu} \operatorname{COV}(h, r)
$$

where $h$ is the health variable, $\mu$ is the mean, and $r$ is the fractional rank of the individual in the wealth index.

When the outcome variable is binary, the concentration index has some questionable properties, especially comparing populations that have significantly different means. In particular, because it is mathematically bound between $\mu-1$ and $1-\mu$ (where $\mu$ is the mean of the binary indicator), it tends to naturally fall (in absolute value) as the value of $\mu$ increases. If only the richest $10 \%$ have access to a health service in the base year, the concentration index would be 0.9 . If the richest $90 \%$ have access to the health service in a subsequent year, the concentration index would be 0.1 . It is therefore debatable whether that should be considered a large decrease in inequality [14, 15]. For binary indicators, we calculated as alternative indicators 
the Wagstaff concentration index $[W=2 / \mu(1-\mu) \operatorname{COV}(h$, $r)]$ and the Erryegers concentration index, $[E=8 \operatorname{COV}(h$, $r)$ ], where $h$ is a health outcome indicator and $r$ is the fractional rank of the individual in the wealth index [14].

Our analysis also included decomposition of the concentration index measure of wealth-related inequalities in selected health outcomes and services. This allowed us to see how differences in, e.g., family size, women's education, and access to safe water contribute to the observed wealth-related inequalities in health outcomes or health services, and how these patterns are changing over time. For example, the observed inequality in childhood vaccination rates might be explained entirely by differences in the mother's education; decomposition of the concentration index would reveal that.

Decomposition of the concentration index is based on the algebraic transformation, which for a linear model of a health indicator

$$
y=\alpha+\sum_{k} \beta_{k} x_{k}+\varepsilon
$$

allows the concentration index to be written as

$$
C=\sum_{k}\left(\beta_{k} \overline{x_{k}} / \mu\right) C_{k}+G C_{\varepsilon} / \mu
$$

where $\mu$ is the mean of $y, \overline{x_{k}}$ is the mean of $x_{k}, C_{k}$ is the concentration index for $x_{k}$, and $C G_{\varepsilon}$ is the generalized concentration index for the error term [15].

The dependent variables of interest in this study are binary indicators and thus best modeled using a nonlinear model such as probit. Following previous work $[15,16])$, the linear approximation is given by the following specification,

$$
h=\alpha^{m}+\sum_{j} \beta_{j}^{m} x_{j}+u
$$

where $h$ is the health variable of interest as defined earlier, $x_{j}$ are the independent variables, $\alpha^{m}$ is the constant term, $\beta_{j}^{m}$ are the partial effects of each variable treated as fixed parameters and evaluated as sample means, and $u$ is the error term. The decomposed concentration index (C) for a health outcome $h_{i}$ is therefore

$$
C=\sum_{j}\left(\beta_{j}^{m} \bar{x}_{j} / \mu\right) C_{j}+G C_{u} / \mu
$$

where $C_{j}$ are the concentration indexes for $x_{j}, \mu$ is the mean of the health variables $h, \bar{x}_{j}$ is the mean of $x_{j}$, and $G C_{u} / \mu$ is the residual component that captures inequality that is not explained by systematic variation in the regressors by income.

\section{Results}

Trends

Table 2 presents the profile and trends of selected $\mathrm{MNCH}$ outcomes and services. As the table makes clear, Ethiopia's
Table 2 Trends in MNCH outcomes in Ethiopia, 2000-2014

\begin{tabular}{llllll}
\hline & 2000 & 2005 & 2011 & 2014 & $\begin{array}{l}\text { Change } \\
\text { (Latest-Earliest) }\end{array}$ \\
\hline Stunting & 57.0 & 49.5 & 44.1 & 40.6 & -16.4 \\
Wasting & 12.5 & 12.4 & 10.1 & 8.9 & -3.6 \\
Underweight & 41.9 & 34.1 & 29.1 & 26.6 & -15.3 \\
NNMR & 48.4 & 39.3 & 37.4 & 34.3 & -14.1 \\
IMR & 95.9 & 77.6 & 58.9 & 59.3 & -36.6 \\
U5MR & 163.9 & 123.3 & 87.1 & 80.1 & -83.8 \\
Measles vaccination & 27.0 & 36.5 & 56.7 & - & 29.7 \\
Full immunization & 14.6 & 21.6 & 24.9 & - & 10.3 \\
Contraceptive & 7.2 & 15.7 & 30.0 & 45.2 & 38.0 \\
ANC4+ & 10.4 & 11.9 & 15.9 & 24.2 & 13.8 \\
SBA & 5.7 & 5.7 & 10.0 & 15.5 & 9.8 \\
\hline
\end{tabular}

Source: Authors' compilation from the EDHS (2000, 2005, 2011 \& 2014) data Notes: The values are number of births per 1000 live births for NMR, IMR and U5MR and percentages for the rest. Earliest survey year is 2000 for all indicators. Latest survey year is 2014 for all but full immunization and measles vaccination, for which our latest source of information is the $2011 \mathrm{DHS}$

health service delivery is among the least developed in low-income countries-modern services reach only a small fraction of the population. For example, the results of the 2014 survey show that nationally modern contraceptive use is $45 \%$. The situation is much worse for ANC visits, where services coverage was $25 \%$, and SBAs, where coverage was $16 \%$. Similarly, full immunization coverage in 2011 was $25 \%$-among the lowest in similar countries in Sub-Saharan Africa. Over the last two decades, however, there has been considerable improvement in $\mathrm{MNCH}$ outcomes in Ethiopia, though child undernutrition and mortality rates are still high and coverage of maternal and health services is low. This holds true for all the health status and health service indicators analyzed in this study (Table 2): There is a consistent decline in ill health (undernutrition and mortality) and an increase in health services coverage (immunizations and maternal health services).

To look at the trends by wealth status, we disaggregated the progress made. For each indicator, each line represents the value of the indicator for one group over time, with the $95 \%$ confidence interval around each value. Figures 1 to 4 present the results for child nutrition, child mortality, immunization, and maternal health services. As expected, as a general pattern the lines for adverse outcomes slope downward for all groups and the lines for health services slope upward, showing $\mathrm{MNCH}$ is improving at all wealth levels; the improvements in average national figures, however, do not hide worsening results for the poor. The distances between the curves and the slope of each curve in each graph show differing initial and final inequality for the indicators.

In Fig. 1, the lines in all graphs move downward basically in parallel, with perhaps a slight widening of the gap 

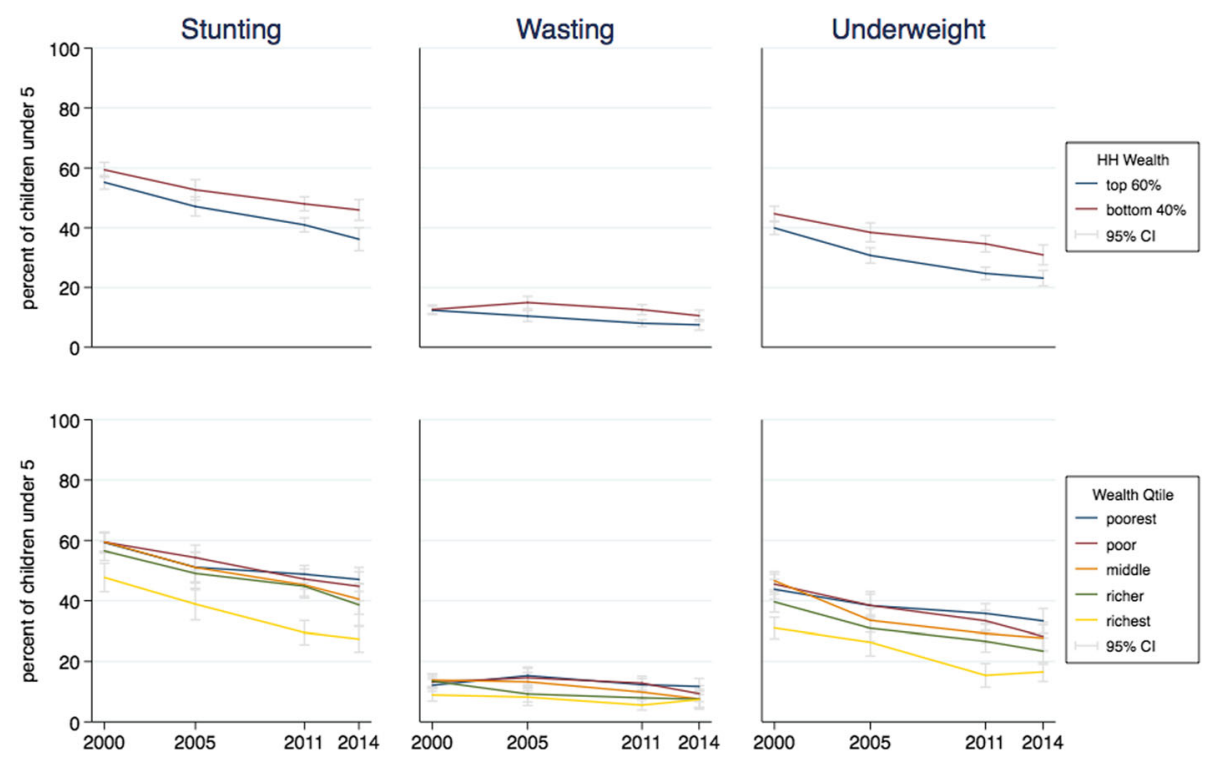

Fig. 1 Trends in child malnutrition by wealth ranking, 2000-2014. Source: DHS 2000 and mini-DHS 2014 data. Notes: Percent of children under 5 years old. Grey lines represent $95 \%$ confidence intervals

between the different wealth groups. In the graph for stunting, we see that inequality is driven by the difference between the richest quintile and the rest, and that this difference is increasing slightly.

Figure 2 shows the trends for child mortality indicators. The biggest improvement has been in the U5MR, with modest improvements in the IMR and essentially no change in neonatal mortality. No clear pattern of wealth-related inequality is observable. The confidence intervals often overlap, showing no significant difference between different groups, and the lines crisscross each other, with poorer households sometimes seeming to have lower child mortality (which might be true and reflect differences in practices like breastfeeding). It is not clear whether it is actually true that there is no systematic difference in child mortality by household wealth level or whether the figures are obscured by the data collection strategy (which only counts children whose mother is alive) or cultural traditions (unwillingness to speak about an infant who died very young).
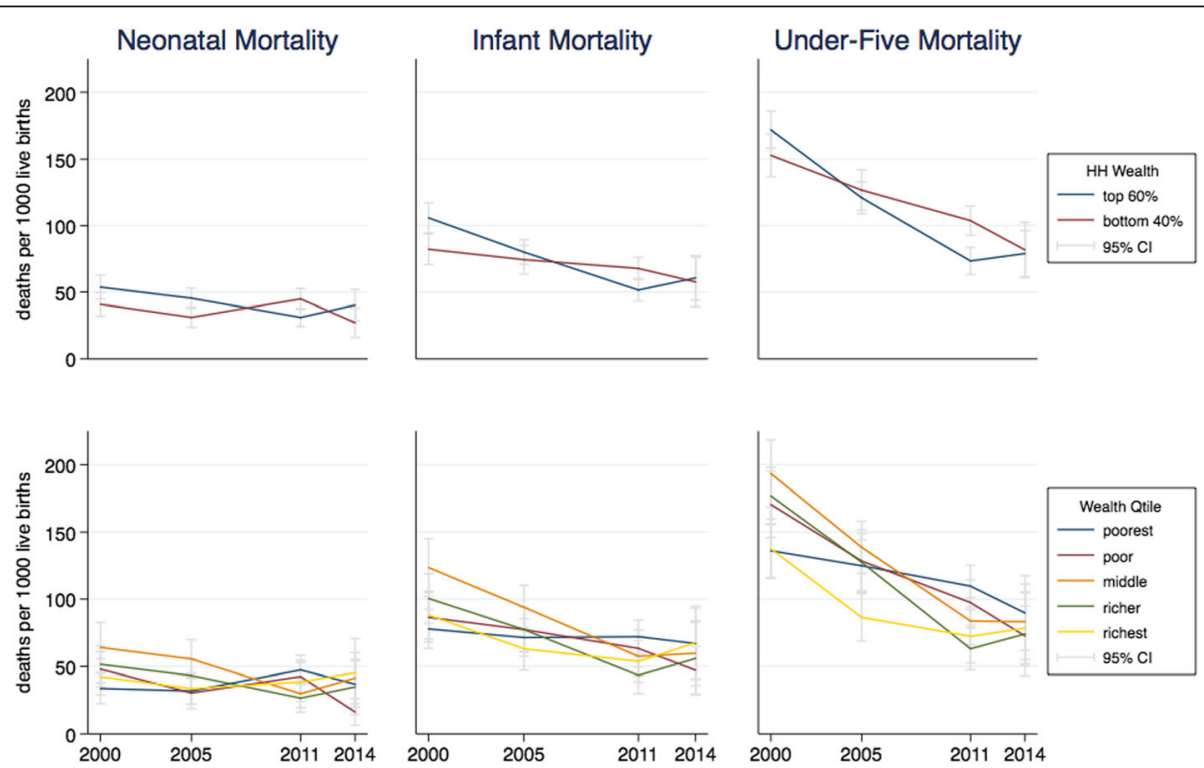

Fig. 2 Trends in child mortality by wealth ranking, 2000-2014. Source: DHS 2000 and mini-DHS 2014 data. Notes: Deaths per 1000 live births. Grey lines represent $95 \%$ confidence intervals 
In Fig. 3, the trends show that immunization services have expanded for all wealth groups, with the lines moving roughly in parallel. Again, the biggest gap is between the richest quintile and all the others.

As Fig. 4 shows, maternal health services have also improved for all groups, but there is a widening of the gap between rich and poor, with a greater increase in the use of maternal health services by richer households. This trend is less pronounced for contraception use, and in fact there seems to be a slight closing of the gap in the last year of data. Again, we see that wealth-based inequality is primarily driven by the difference between the wealthiest quintile and the rest, especially for ANC and SBA.

\section{Absolute and relative inequalities}

The figures in the previous section give us a good indication of the general trends: fairly consistent improvements across all wealth groups, with some modest narrowing or widening of gaps depending on the indicator and the exact breakdown of households by wealth. To quantify and test the statistical significance of these observations, we report the results from eqs. 1 and 2 in Tables 3 and 4 . The results in Table 3 compare the bottom $40 \%$ of households and the top $60 \%$. Those in Table 4 compare the bottom quintile to the top quintile. In each table, the first section gives the value of the indicator for "poor" and "rich" households in both the first and the last year. The second shows the absolute inequality (the difference between the values of the indicator for the two groups) in the earliest and the latest survey and the $p$-value for whether absolute inequality changed significantly during that period. The third section shows the relative inequality (the ratio of the indicators) and the $p$-value for whether it has changed significantly. A positive difference or ratio greater than 1 for an ill-health outcome (child undernutrition or child mortality) shows a pro-rich inequality-child undernutrition and mortality rates were lower for children from better-off households. Likewise, a negative difference or ratio less than 1 in any of the immunization and maternal health service indicators (good health service utilization) implies pro-rich inequality. These socioeconomic differences are to be expected; our interest is in whether the differences are increasing or decreasing.

The results (Table 3) point to a widening of absolute prorich inequality in child nutritional outcomes between the poor (bottom 40\%) and the rich (top 60\%)-an inequality observed in all three child nutrition status indicators but more significant for stunting and underweight. For the poor, child stunting in the earliest survey was higher by about 4.2 percentage points and in the latest the difference rises to 10 percentage points. Similarly, the gap in underweight went up from 5 to 8 percentage points. In both cases, these changes are statistically significant, which implies that pro-rich inequality is widening. The same conclusions can be drawn when looking at relative inequalities: pro-rich inequality widened significantly during the period considered, at least for stunting and underweight.

When we restrict our analysis to the poorest versus the richest quintile (Table 4), the trend recurs: an everincreasing gap between the rich and the poor in terms of child nutrition. These changes are less statistically significant, however, and only the relative inequality in
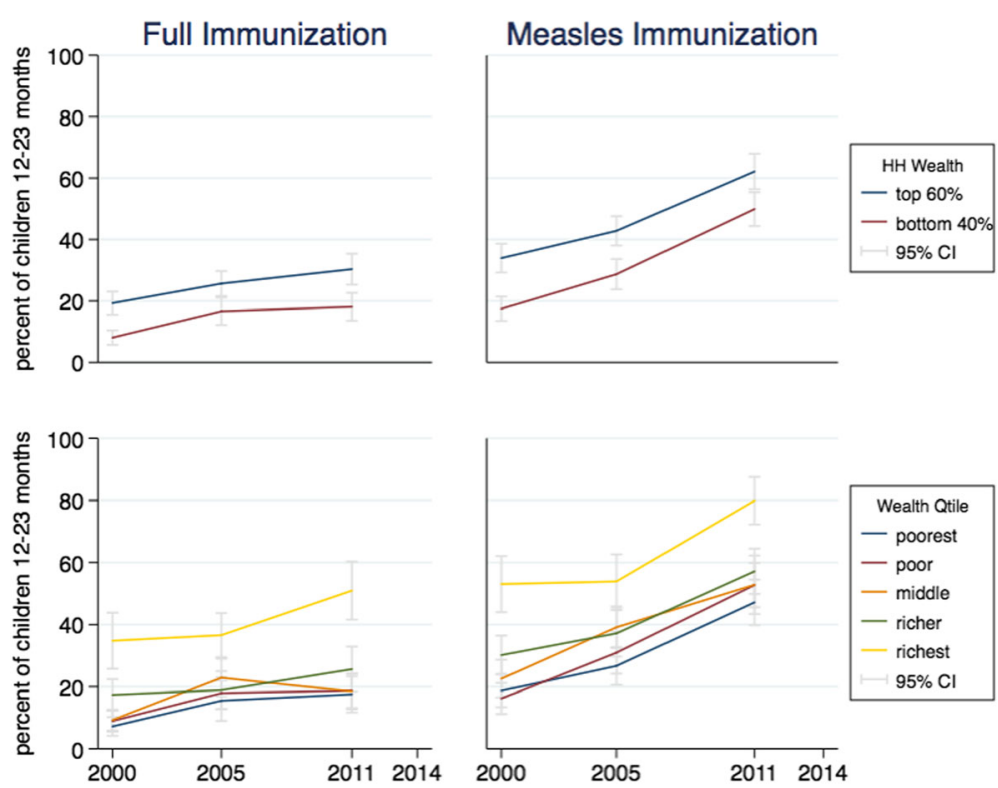

Fig. 3 Trends in child immunization by wealth ranking, 2000-2011. Source: DHS 2000 and 2011 data. Notes: Percent of children 12-23 months old. Grey lines represent 95\% confidence intervals 

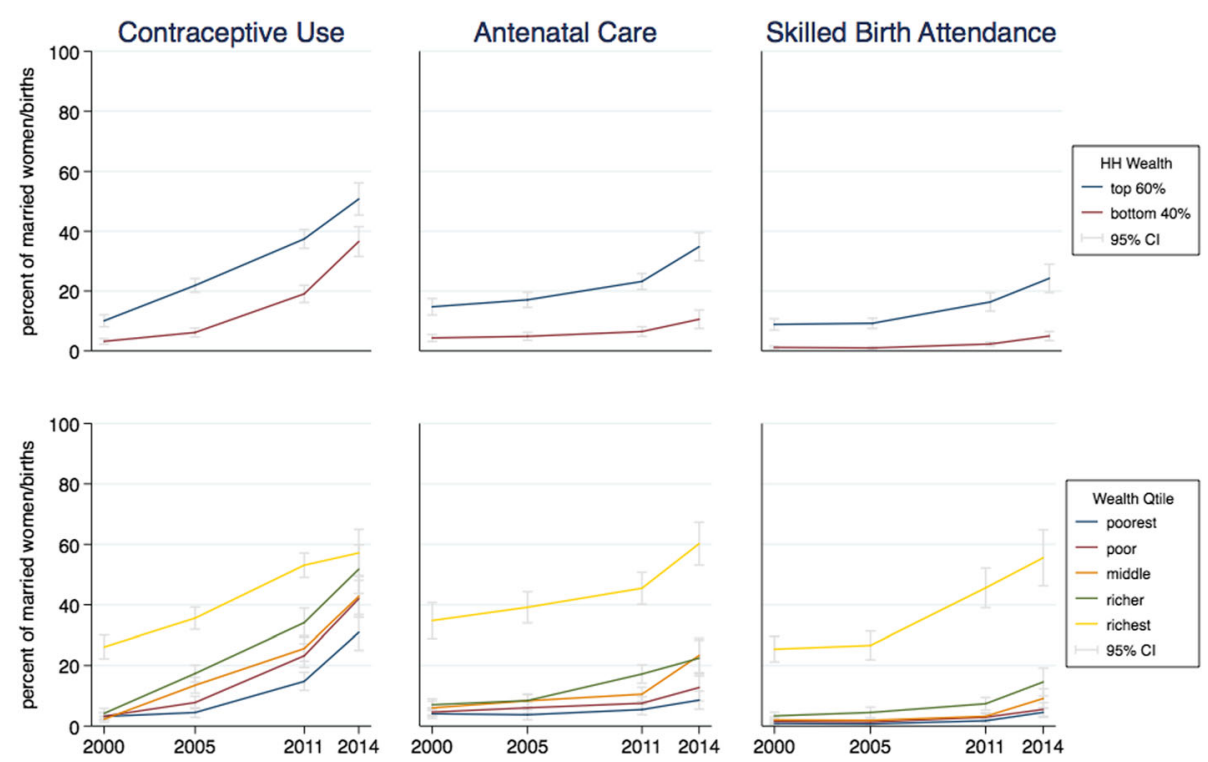

Fig. 4 Trends in maternal health services by wealth ranking, 2000-2014. Source: DHS 2000 and mini-DHS 2014 data. Note: Percent of married women/births. Grey lines represent $95 \%$ confidence intervals

stunting between the richest and the poorest changes significantly.

The results for infant and child mortality appear to show that mortality rates were in fact lower for poorer households in the first survey (the values for the difference between rich and poor are negative in all three indicators and in both ways of defining rich and poor). Then, by the final survey, the pro-poor gap appears to have disappeared for infant mortality and is reversed for under-5 mortality, with both rates higher for poorer households. While these figures may represent real changes in mortality patterns, it should be noted that the standard errors on the mortality rates for different subgroups are quite high, and that none of the changes over time are statistically significant.

For all services except measles vaccination, in the first survey, utilization by poorer households was very low; thus while the difference between the rates increased (significantly in the case of maternal health services), which suggests widening inequality, the ratio of the rates decreased, suggesting that inequality had narrowed. For measles vaccination, both the variances and the ratio suggest decreasing inequality, although only the changes in the ratio are significant.

Table 3 Trends in MNCH between poor and rich households, 2000-2014

\begin{tabular}{|c|c|c|c|c|c|c|c|c|c|c|}
\hline & \multicolumn{2}{|c|}{ Top 60\% } & \multicolumn{2}{|c|}{ Bottom $40 \%$} & \multicolumn{3}{|c|}{ Difference } & \multicolumn{3}{|l|}{ Ratio } \\
\hline & $\begin{array}{l}\text { Earliest } \\
\text { Survey }\end{array}$ & $\begin{array}{l}\text { Latest } \\
\text { Survey }\end{array}$ & $\begin{array}{l}\text { Earliest } \\
\text { Survey }\end{array}$ & $\begin{array}{l}\text { Latest } \\
\text { Survey }\end{array}$ & $\begin{array}{l}\text { Earliest } \\
\text { Survey }\end{array}$ & $\begin{array}{l}\text { Latest } \\
\text { Survey }\end{array}$ & $p$-value & $\begin{array}{l}\text { Earliest } \\
\text { Survey }\end{array}$ & $\begin{array}{l}\text { Latest } \\
\text { Survey }\end{array}$ & $p$-value \\
\hline Stunting & 55.2 & 36.2 & 59.4 & 45.9 & -4.2 & -9.8 & 0.064 & 0.9 & 0.8 & 0.013 \\
\hline Wasting & 12.4 & 7.5 & 12.7 & 10.6 & -0.3 & -3.0 & 0.077 & 1.0 & 0.7 & 0.034 \\
\hline Underweight & 39.9 & 23.1 & 44.7 & 30.9 & -4.7 & -7.8 & 0.189 & 0.9 & 0.7 & 0.011 \\
\hline NNMR & 53.8 & 40.3 & 40.9 & 27.1 & 12.9 & 13.2 & 0.977 & 1.3 & 1.5 & NA \\
\hline IMR & 105.8 & 60.7 & 82.2 & 57.7 & 23.6 & 3.0 & 0.176 & 1.3 & 1.1 & NA \\
\hline U5MR & 171.9 & 79.0 & 152.7 & 81.7 & 19.2 & -2.7 & 0.212 & 1.1 & 1.0 & NA \\
\hline Measles vaccination & 33.9 & 62.1 & 17.5 & 49.9 & 16.5 & 12.2 & 0.354 & 1.9 & 1.2 & 0.006 \\
\hline Full immunization & 19.3 & 30.3 & 8.1 & 18.1 & 11.2 & 12.2 & 0.796 & 2.4 & 1.7 & 0.143 \\
\hline Contraceptive & 10.1 & 50.8 & 3.2 & 36.6 & 6.9 & 14.2 & 0.033 & 3.2 & 1.4 & 0.002 \\
\hline ANC4+ & 14.8 & 34.8 & 4.3 & 10.6 & 10.4 & 24.2 & 0.000 & 3.4 & 3.3 & 0.876 \\
\hline SBA & 8.9 & 24.2 & 1.2 & 5.0 & 7.7 & 19.3 & 0.000 & 7.5 & 4.9 & 0.142 \\
\hline
\end{tabular}

Source: Authors' compilation from the EDHS (2000, 2005, 2011 \& 2014) data

Notes: Indicators are given in percentage points except for mortality rates, which are number of deaths per 1000 live births. The earliest year is 2000 for all indicators. The latest year is 2014 for all indicators except immunization (full and measles), for which it is 2011 
Table 4 Trends in MNCH between poorest and richest households, 2000-2014

\begin{tabular}{|c|c|c|c|c|c|c|c|c|c|c|}
\hline & \multicolumn{2}{|c|}{ Richest Quintile } & \multicolumn{2}{|c|}{ Poorest Quintile } & \multicolumn{3}{|c|}{ Difference } & \multicolumn{3}{|l|}{ Ratio } \\
\hline & $\begin{array}{l}\text { Earliest } \\
\text { Survey }\end{array}$ & $\begin{array}{l}\text { Latest } \\
\text { Survey }\end{array}$ & $\begin{array}{l}\text { Earliest } \\
\text { Survey }\end{array}$ & $\begin{array}{l}\text { Latest } \\
\text { Survey }\end{array}$ & $\begin{array}{l}\text { Earliest } \\
\text { Survey }\end{array}$ & $\begin{array}{l}\text { Latest } \\
\text { Survey }\end{array}$ & $p$-val & $\begin{array}{l}\text { Earliest } \\
\text { Survey }\end{array}$ & $\begin{array}{l}\text { Latest } \\
\text { Survey }\end{array}$ & $p$-val \\
\hline Stunting & 47.7 & 27.4 & 59.3 & 47.1 & -11.6 & -19.7 & 0.057 & 0.8 & 0.6 & 0.002 \\
\hline Wasting & 8.9 & 7.4 & 12.1 & 11.7 & -3.2 & -4.3 & 0.656 & 0.7 & 0.6 & 0.559 \\
\hline Underweight & 31.0 & 16.6 & 43.8 & 33.4 & -12.8 & -16.8 & 0.237 & 0.7 & 0.5 & 0.003 \\
\hline NNMR & 42.3 & 45.3 & 33.7 & 36.8 & 8.6 & 8.4 & 0.991 & 1.3 & 1.2 & NA \\
\hline IMR & 88.2 & 67.7 & 77.9 & 67.0 & 10.3 & 0.7 & 0.669 & 1.1 & 1.0 & NA \\
\hline U5MR & 137.6 & 78.4 & 136.1 & 89.7 & 1.5 & -11.3 & 0.603 & 1.0 & 0.9 & NA \\
\hline Measles vaccination & 53.1 & 79.9 & 18.7 & 47.1 & 34.3 & 32.8 & 0.825 & 2.8 & 1.7 & 0.023 \\
\hline $\begin{array}{l}\text { Full } \\
\text { immunization }\end{array}$ & 34.8 & 50.9 & 7.2 & 17.5 & 27.6 & 33.4 & 0.419 & 4.8 & 2.9 & 0.153 \\
\hline Contraceptive & 26.1 & 57.2 & 3.2 & 30.9 & 23.0 & 26.2 & 0.538 & 8.3 & 1.8 & 0.000 \\
\hline ANC4+ & 34.8 & 60.2 & 4.1 & 8.6 & 30.7 & 51.7 & 0.000 & 8.6 & 7.0 & 0.481 \\
\hline SBA & 25.4 & 55.6 & 0.9 & 4.5 & 24.5 & 51.0 & 0.000 & 29.6 & 12.3 & 0.060 \\
\hline
\end{tabular}

Source: Authors' compilation from the EDHS (2000, 2005, 2011 \& 2014) data

Notes: Indicators are given in percentage points except for mortality rates, which are number of deaths per 1000 live births. The earliest year is 2000 for all indicators. The latest year is 2014 for all indicators except immunization (full and measles), for which it is 2011

\section{Concentration curves and indexes}

The concentration curves in Fig. 5 show child malnutrition as fairly even distributed across income categories, with the curves lying close to the line of equality, but the curves moving away from the line indicate gradually increasing inequality. Overall, the results presented here are aligned with the findings already presented: the poor did not benefit as much from the improvements in child nutritional status.

Figure 6 shows the concentration curves for child mortality indicators. Here the curves overlap and some cross the line of equity. This reflects the fact that there are no obvious patterns or trends when mortality rates are broken down by household wealth level. Statistical tests confirm that for these indicators there is no significant change in wealth-based inequality.

Figs. 7 and 8 illustrate the movement of wealth-related inequalities in child immunizations and maternal health services. Here there is clearly significant inequality, with the concentration curves lying far below the line of equality. However, we also see substantial movement over time as the curves move closer to the line of equality, reflecting less wealth-based inequality in use of services. The figure for antenatal care shows clearly that improvements are concentrated among richer households - middle-ranked households are catching up to the wealthiest households, but the poorest households are not catching up to those in the middle.

For each indicator, Table 5 provides information on the concentration index and, for binary indicators, the alternative Wagstaff and Erryegers concentration indexes for the earliest and latest years. Note that, as expected, the index values are negative for malnutrition indicators-richer households have less malnutrition-and positive for $\mathrm{MNCH}$ services-richer households use health services more. The values of the concentration indexes for mortality can be either positive or negative; there is no clear trend. The absolute value of the concentration index can be taken as a measure of the inequality present. The tables also show the result of simple t-tests of whether the concentration index value changed significantly between the first and the last survey.

The concentration indexes for all three undernutrition indicators show pro-rich inequality heightening; in absolute value the concentration index more than doubled for all three, although from initially low levels of inequality. The changes are significant for stunting and underweight. Using the Wagstaff or the Erryegers concentration index yields the same result but with somewhat less significance. On the other hand, like the concentration curves (Fig. 5), there is no clear pattern in the indexes for mortality indicators (Table 5). Table 5 also shows mixed progress in decreasing inequality in the use of $\mathrm{MNCH}$ services; over time concentration index values decrease, but except for measles vaccination and contraceptive use the changes are not significant when the Wagstaff concentration index is used. However, the Erryegers concentration index leads to the opposite conclusions: it shows increasing inequality in four of the five indicators and is significant for maternal health services. This again reflects the pattern we see, particularly in maternal health services: having expanded rapidly from low levels tends to lead to a decrease in the standard concentration index that is not robust to using the Erryegers index.

Despite progress then, as both the concentration curves and indexes illustrate, inequalities are still substantial in the case of ANC4+ and SBA. 

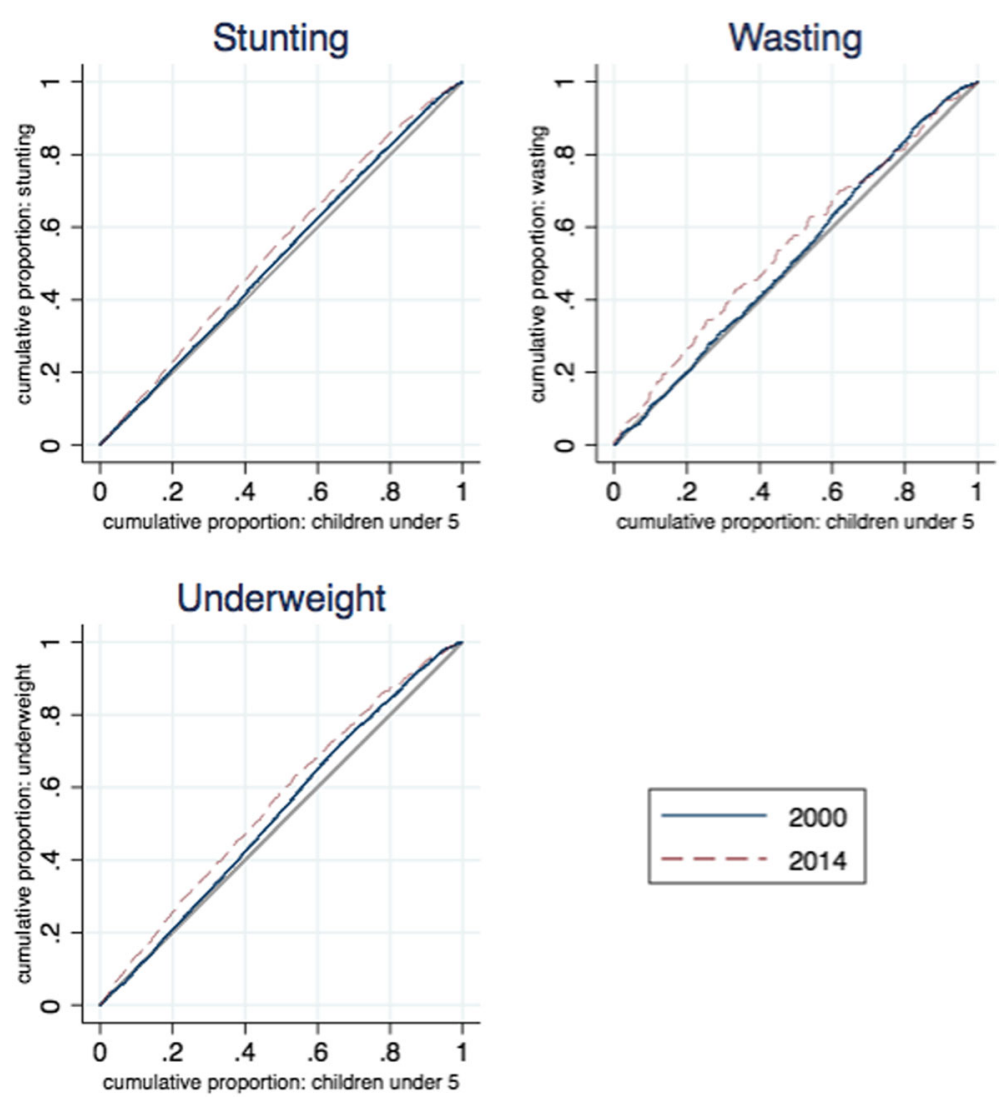

Fig. 5 Concentration curves of child nutritional status, 2000-2014. Source: DHS 2000 and mini-DHS 2014 data. Note: Percent of children under 5 years old

\section{Changes in inequality}

We used three different methods to assess changes over time in wealth-related inequality in indicators of health status and health service utilization: rate differences, rate ratios, and concentration indices. Table 6 summarizes the results.

Although child malnutrition has been reduced for all income groups, wealth-based inequality worsened over the period studied. This pattern is consistent for all three indicators and all methods of analysis.

The DHS data show no clear relationship between household wealth and child mortality. In earlier years, there may have been inequality in favor of poorer households, or possibly an inverse-U shaped pattern, with households in the middle of the wealth distribution having the highest child mortality. That pattern might be explained by cultural factors, or it might be an artifact of the data collection strategy. The concentration index suggests there is some evidence that inequality in child mortality has "improved," moving from a pro-poor bias to a smaller pro-poor bias or a small pro-rich bias.

Inequality has narrowed slightly in child vaccination services, particularly for measles vaccinations. For maternal health services, the results seem contradictory: The absolute difference in maternal health service utilization by the rich and the poor has increased, but initially service use by poor households was extremely low and the gains they have made are substantial. Thus, the rate ratio, the concentration curves, and two of the three concentration indexes analyzed all rate the changes as a decrease in inequality.

\section{Decomposition}

The analyses so far discussed demonstrate that, despite improvements, there are still considerable inequalities in some $\mathrm{MNCH}$ outcomes and services. In this section, we examine what may be contributing to the wealth-related inequalities in certain indicators.

Tables 7 to 9 present the decomposition of concentration indexes for selected indicators. Various controls that may be related to both wealth status and the value of the indicator are included to see how much of the inequality can be attributed to factors like the mother's education or adequate sanitation facilities.

Table 7 summarizes the results for stunting: in each year, even when controlling for other variables, the largest contribution comes from the wealth index. The next largest comes from mother's education. Comparing the progression of stunting between 2000 and 2014, we see that the increased inequality comes only from the contribution 

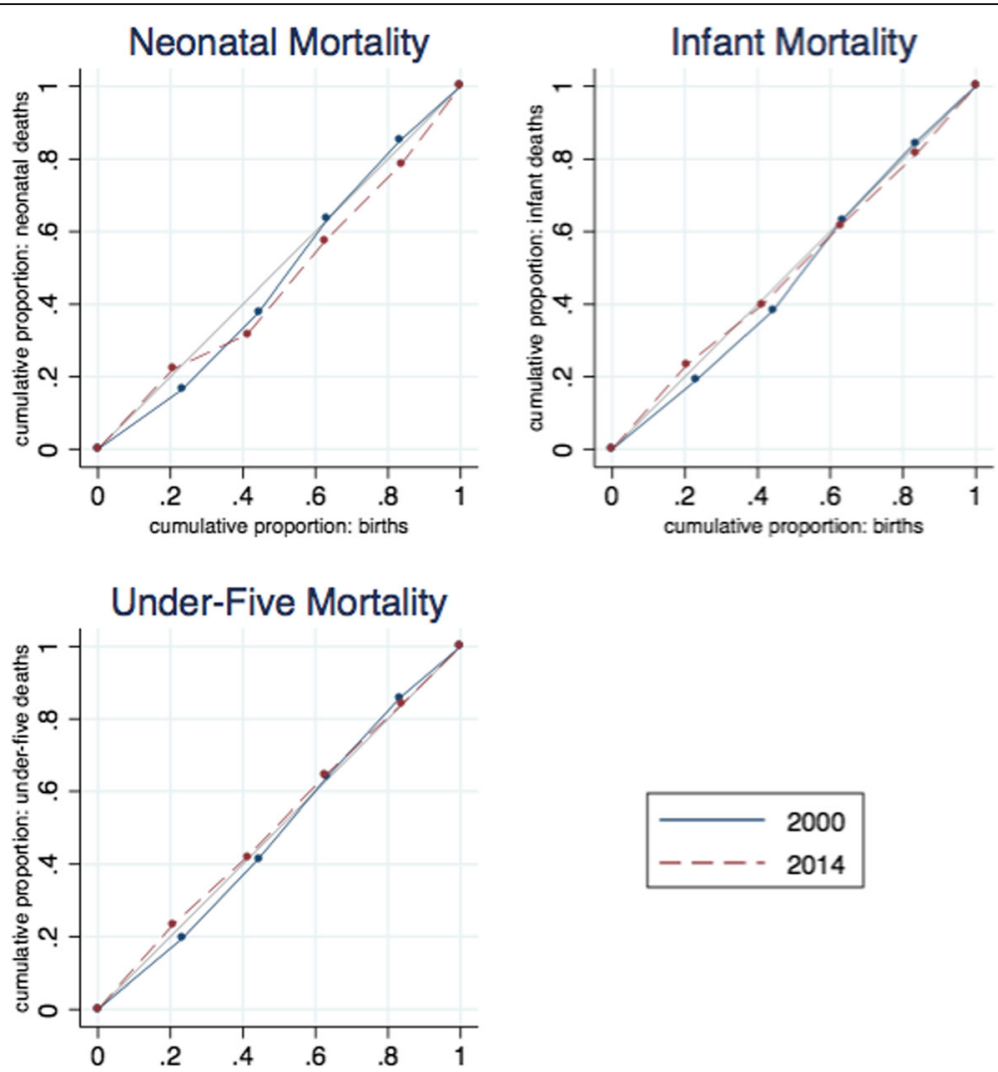

Fig. 6 Concentration curves of child mortality, 2000-2011. Source: DHS 2000 and mini-DHS 2014 data

of the wealth index itself, not from any other factors. The decomposition for 2014 has a large positive residual component, however, suggesting that other factors not captured in the decomposition are in fact offsetting the rise in wealth-related inequality in stunting.
Table 8 shows the decomposition for measles vaccination (Panel a) and full immunization (Panel b). Comparing results in 2000 and 2014, we see that for measles vaccination the contribution of the wealth index has gone from being the largest to being one of the smallest
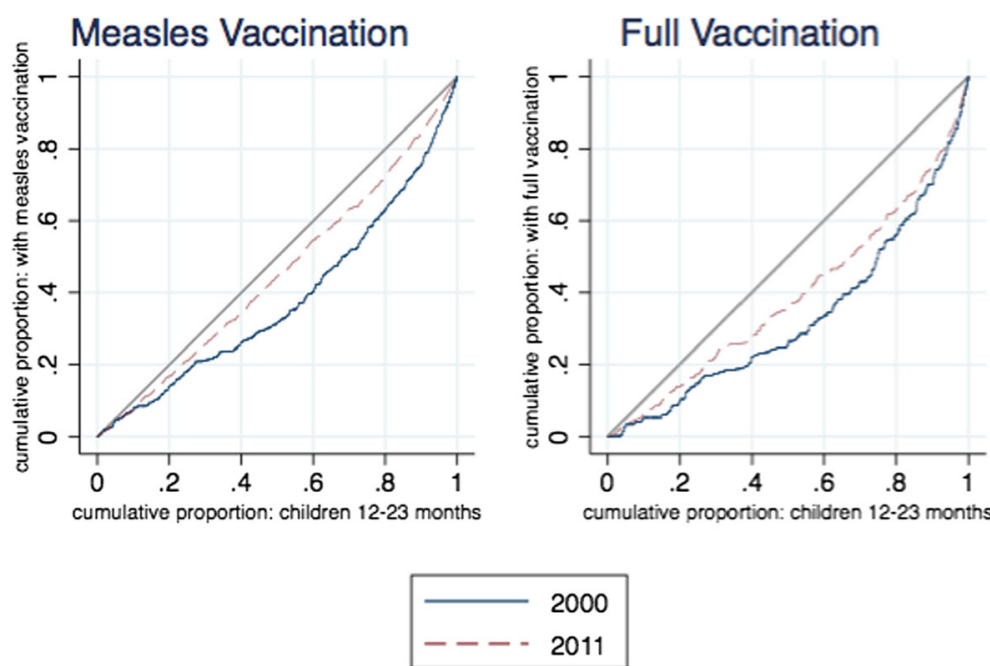

Fig. 7 Concentration curves of child immunization coverage, 2000-2011. Source: DHS 2000 and 2011 data. Notes: Percent of children 12-23 months old 

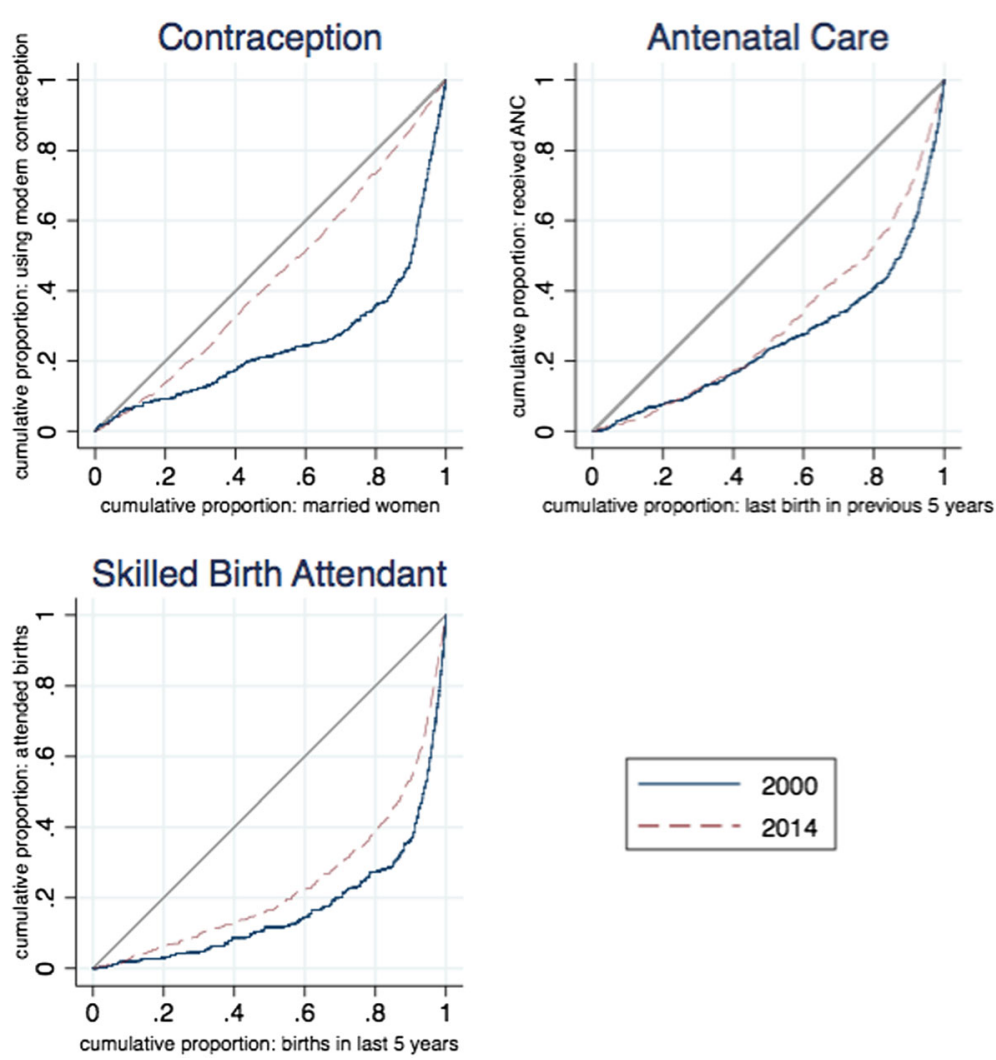

Fig. 8 Concentration curves of selected maternal health services, 2000-2014. Source: DHS 2000 and mini-DHS 2014 data

but when all immunizations are considered it was still very important. This suggests that the pure wealth component of inequality in measles vaccinations almost disappeared when coverage was expanded, as it was for measles vaccination but not full immunization. In both cases, the remaining inequalities can be explained almost entirely by differences in the education of the mother and the father.

In Table 9 Panels a through c present the decomposition results for maternal health services. A serious limitation is that in all specifications the residual component is large. With that in mind, however, it is still possible to

Table 5 Concentration indexes of selected child health status indicators in Ethiopia, 2000-2014

\begin{tabular}{|c|c|c|c|c|c|c|c|c|c|}
\hline & \multicolumn{3}{|c|}{ Concentration Index } & \multicolumn{3}{|c|}{ Wagstaff Concentration Index } & \multicolumn{3}{|c|}{ Erryegers Concentration Index } \\
\hline & Earliest & Latest & $p$-val & Earliest & Latest & $p$-val & Earliest & Latest & $p$-val \\
\hline Stunting & -0.032 & -0.086 & 0.001 & -0.075 & -0.145 & 0.018 & -0.074 & -0.140 & 0.021 \\
\hline Wasting & -0.034 & -0.102 & 0.105 & -0.039 & -0.112 & 0.116 & -0.017 & -0.036 & 0.240 \\
\hline Underweight & -0.054 & -0.119 & 0.003 & -0.093 & -0.162 & 0.025 & -0.091 & -0.127 & 0.163 \\
\hline NNMR & 0.049 & 0.075 & 0.000 & 0.052 & 0.078 & 0.000 & - & - & - \\
\hline IMR & 0.038 & 0.008 & 0.000 & 0.042 & 0.009 & 0.000 & - & - & - \\
\hline U5MR & 0.016 & -0.022 & 0.000 & 0.019 & -0.024 & 0.000 & - & - & - \\
\hline Measles vaccination & 0.242 & 0.096 & 0.000 & 0.331 & 0.223 & 0.043 & 0.261 & 0.219 & 0.368 \\
\hline Full immunization & 0.344 & 0.223 & 0.025 & 0.403 & 0.297 & 0.110 & 0.201 & 0.22 & 0.594 \\
\hline Contraceptive & 0.496 & 0.119 & 0.000 & 0.534 & 0.218 & 0.000 & 0.142 & 0.216 & 0.009 \\
\hline ANC4+ & 0.474 & 0.381 & 0.017 & 0.529 & 0.503 & 0.578 & 0.197 & 0.369 & 0.000 \\
\hline SBA & 0.665 & 0.525 & 0.004 & 0.705 & 0.622 & 0.116 & 0.150 & 0.325 & 0.000 \\
\hline
\end{tabular}

Source: Authors' compilation from the EDHS (2000, 2005, 2011 \& 2014) data

Note: Latest survey for immunization indicators is 2011 
Table 6 Summary of results of changes in income related MNCH inequalities, 2000-2014

\begin{tabular}{|c|c|c|c|c|c|c|c|}
\hline & \multicolumn{2}{|l|}{ Rate Differences } & \multicolumn{2}{|l|}{ Rate Ratio } & \multirow{2}{*}{$\begin{array}{l}\text { Conc. } \\
\text { Index }\end{array}$} & \multicolumn{2}{|c|}{ Test of Dominance: Concentration Curves } \\
\hline & $\begin{array}{l}\text { Bottom } 40 \% \text { vs. } \\
\text { Top } 60 \%\end{array}$ & $\begin{array}{l}\text { Poorest (q1) vs. } \\
\text { Richest (q5) }\end{array}$ & $\begin{array}{l}\text { Bottom } 40 \% \text { vs. } \\
\text { Top } 60 \%\end{array}$ & $\begin{array}{l}\text { Poorest (q1) vs. } \\
\text { Richest (q5) }\end{array}$ & & mca rule & iup rule \\
\hline \multicolumn{8}{|l|}{ Panel A: Health Status } \\
\hline Stunting & Worsened & Worsened & Worsened & Worsened & Worsened & NS & NS \\
\hline Wasting & Worsened & NS & Worsened & NS & NS & Worsened & NS \\
\hline Underweight & NS & NS & Worsened & Worsened & Worsened & Worsened & NS \\
\hline $\mathrm{NMR}^{\mathrm{a}}$ & NS & NS & - & - & Improved $^{\mathrm{a}}$ & - & - \\
\hline $\mathrm{IMR}^{\mathrm{a}}$ & NS & NS & - & - & Improved $^{\mathrm{a}}$ & - & - \\
\hline U5MR & NS & NS & - & - & Improved $^{\mathrm{a}}$ & - & - \\
\hline \multicolumn{8}{|c|}{ Panel B: Health Services } \\
\hline Measles vaccination & NS & NS & Improved & Improved & Improved & Improved & NS \\
\hline Full immunization & NS & NS & NS & NS & Improved $^{\mathrm{b}}$ & NS & NS \\
\hline Contraceptive & Worsened & NS & Improved & Improved & Improved & Improved & NS \\
\hline ANC4+ & Worsened & Worsened & NS & NS & Improved $^{b}$ & Improved & NS \\
\hline SBA & Worsened & Worsened & NS & Improved & Improved $^{\mathrm{b}}$ & Improved & Improved \\
\hline
\end{tabular}

Notes: The table summarizes results of different approaches presented in the previous sections and the test of dominance. The test of dominance is based on [15]. The number of evenly spaced quintile points is 19 (from 5\% to 95\%) and the significance level is $5 \%$. The dominance test rules, mca and iup, respectively denote the multiple comparison approach and the intersection union principle. "-" is test not applicable. NS is no significant change from the earliest survey

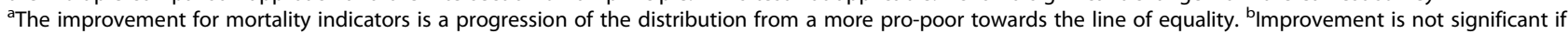
Wagstaff concentration index is used

discern some common trends: there is only a slight decline in inequalities over the period, the prevailing inequalities are still high, and the wealth index, education, and residence of the user all make important contributions to the differences in utilization of these services.

\section{Discussion}

In examining differential progress in health status and health services utilization in Ethiopia, we used a variety of methods to look at inequalities by household wealth in selected $\mathrm{MNCH}$ indicators. We are able to make three main observations:

Table 7 Decomposition of concentration index for stunting (2000-2014)

\begin{tabular}{|c|c|c|c|c|c|c|}
\hline & \multicolumn{3}{|l|}{2000} & \multicolumn{3}{|l|}{2014} \\
\hline & Elasticity & Conc. index & Contribution & Elasticity & Conc. index & Contribution \\
\hline Child age & 1.639 & -0.003 & -0.004 & 2.202 & -0.011 & -0.025 \\
\hline Child age squared & -0.862 & -0.004 & 0.003 & -1.168 & -0.016 & 0.018 \\
\hline Sex (Male) & 0.028 & -0.004 & 0.000 & 0.031 & 0.010 & 0.000 \\
\hline Birth order & 0.010 & -0.068 & -0.001 & -0.048 & -0.024 & 0.001 \\
\hline Wealth index & -0.192 & 0.142 & -0.027 & -0.310 & 0.180 & -0.056 \\
\hline Child HH members & 0.038 & -0.016 & -0.001 & 0.000 & -0.033 & 0.000 \\
\hline HH size & -0.008 & -0.025 & 0.000 & 0.057 & 0.005 & 0.000 \\
\hline Education (mother) & -0.020 & 0.531 & -0.011 & -0.037 & 0.460 & -0.017 \\
\hline Education (HH head) & -0.018 & 0.347 & -0.006 & -0.026 & 0.349 & -0.009 \\
\hline Residence (urban) & 0.010 & 0.848 & 0.009 & -0.013 & 0.709 & -0.009 \\
\hline Region & & . & -0.005 & & . & -0.001 \\
\hline Residual & . & . & 0.010 & . & . & 0.055 \\
\hline Total & . & . & -0.033 & & & -0.042 \\
\hline
\end{tabular}

Notes: Child $\mathrm{HH}$ members are household members under 5 years of age. $\mathrm{HH}$ size is total household size. Regions are dummies for each region with one reference region (Tigray) omitted from the regressions 
Table 8 Decomposition of concentration index for immunization indicators (2000-2011)

\begin{tabular}{|c|c|c|c|c|c|c|}
\hline \multirow[b]{2}{*}{ 8a. Measles Vaccination } & \multicolumn{3}{|l|}{2000} & \multicolumn{3}{|l|}{2011} \\
\hline & Elasticity & Conc. ind & Contribution & Elasticity & Conc. ind & Contribution \\
\hline Age (mother's) & 0.124 & -0.023 & -0.003 & 0.304 & 0.000 & 0.000 \\
\hline Child HH members & -0.011 & -0.014 & 0.000 & -0.073 & -0.030 & 0.002 \\
\hline HH size & -0.036 & -0.027 & 0.001 & -0.109 & -0.005 & 0.001 \\
\hline Wealth index & 1.437 & 0.098 & 0.141 & 0.856 & 0.104 & 0.089 \\
\hline Education (mother) & 0.057 & 0.518 & 0.029 & 0.070 & 0.486 & 0.034 \\
\hline Education (father) & 0.107 & 0.407 & 0.043 & 0.024 & 0.364 & 0.009 \\
\hline Residence (urban) & -0.006 & 0.885 & -0.005 & -0.011 & 0.800 & -0.009 \\
\hline Region & . & . & 0.004 & . & & -0.001 \\
\hline Residual & . & . & 0.031 & . & & -0.029 \\
\hline Total & & . & 0.242 & . & & 0.096 \\
\hline \multicolumn{7}{|l|}{ 8b. Full Immunization } \\
\hline Age (mother's) & 0.096 & -0.023 & -0.002 & 0.362 & 0.000 & 0.000 \\
\hline Child HH members & 0.015 & -0.014 & 0.000 & -0.091 & -0.030 & 0.003 \\
\hline HH size & 0.065 & -0.027 & -0.002 & -0.207 & -0.005 & 0.001 \\
\hline Wealth Index & 1.409 & 0.098 & 0.138 & 2.434 & 0.104 & 0.253 \\
\hline Education (mother) & 0.110 & 0.525 & 0.058 & 0.042 & 0.486 & 0.021 \\
\hline Education (father) & 0.112 & 0.412 & 0.046 & 0.000 & 0.363 & 0.000 \\
\hline Residence (urban) & -0.021 & 0.906 & -0.019 & -0.065 & 0.800 & -0.052 \\
\hline Region & . & . & . & . & & -0.005 \\
\hline Residual & . & . & . & . & & 0.002 \\
\hline Total & . & . & 0.344 & . & & 0.223 \\
\hline
\end{tabular}

Notes: Child HH members are household members under 5 years of age. $\mathrm{HH}$ size is total household size. Regions are dummies for each region with one reference region (Tigray) omitted from the regressions

(1) According to trend analysis, there has been substantial progress in $\mathrm{MNCH}$ services and outcomes over the study period. DHS data for 2000-14 show that child undernutrition and mortality have declined considerably and health services coverage has increased. Indeed, Ethiopia is one of the few countries that achieved its MDG4 (child mortality reduction) three years ahead of schedule, by three years. As in many other countries, that may partly be due to its economic performance during the past decade and the related improvements in living conditions. A recent poverty assessment study found that in 11 years head-count poverty dropped by 24 percentage points, from $55 \%$ in 2000 to $31 \%$ in 2011 [17]. Ethiopia's health system may also have made an indispensable contribution. In the period from 1997 to 2015, the Health Sector Development Programs (HSDP) allocated resources to priority health outcomes and made services locally available through power devolution and expansion of infrastructure and human resources [18].

(2) The results of the analyses of wealth-related inequalities are mixed. Over time, there has been a narrowing of wealth-based inequalities in health services (measles and full vaccination, contraception, ANC4. + , and SBA). This is encouraging. It suggests that further expansion in their coverage could substantially reduce the remaining inequalities. However, we also find that for the poor, health outcomes have worsened, and the gap in child malnutrition between rich and poor households has widened. Patterns in childhood mortality may also have shifted from a modest pro-poor bias to a modest pro-rich one. This finding on the disconnect between health services and health outcomes agrees with previous studies for a number of developing countries [4]. However, the considerable decline in health services inequality could be attributable to the country's flagship Health Extension Program, which may have helped significantly to making services more available, particularly to the poor. The program deployed over 38,000 health extension workers (HEWs) to local communities for health promotion and basic service delivery [19]. As a lower-cadre alternative in their own or neighboring communities, these HEWs reached poor Ethiopians more effectively than medical doctors and nurses. However, because improving health and nutritional outcomes among the poor requires 
Table 9 Decomposition of concentration index for maternal health services (2000-2014)

\begin{tabular}{|c|c|c|c|c|c|c|}
\hline \multirow[b]{2}{*}{ 9a. Contraceptive } & \multicolumn{3}{|l|}{2000} & \multicolumn{3}{|l|}{$2011 / 14$} \\
\hline & Elasticity & Conc. index & Contribution & Elasticity & Conc. index & Contribution \\
\hline Age & -0.481 & -0.019 & 0.009 & -0.768 & -0.006 & 0.004 \\
\hline Wealth index & 1.028 & 0.099 & 0.102 & 0.780 & 0.101 & 0.079 \\
\hline Education (years) & 0.067 & 0.562 & 0.038 & 0.062 & 0.432 & 0.027 \\
\hline Residence (urban) & 0.152 & 0.817 & 0.124 & 0.067 & 0.636 & 0.043 \\
\hline Protestant & -0.014 & -0.044 & 0.001 & 0.013 & -0.019 & 0.000 \\
\hline Muslim & 0.046 & -0.018 & -0.001 & -0.073 & -0.041 & 0.003 \\
\hline No more children & 0.275 & 0.020 & 0.006 & 0.096 & 0.002 & 0.000 \\
\hline Region & . & . & -0.009 & . & . & 0.003 \\
\hline Residual & & . & 0.227 & . & . & 0.224 \\
\hline Total & . & . & 0.496 & . & . & 0.382 \\
\hline \multicolumn{7}{|l|}{ 96. ANC4+ } \\
\hline Age & 0.102 & -0.020 & -0.002 & -0.404 & -0.005 & 0.002 \\
\hline Wealth index & 1.430 & 0.100 & 0.143 & 1.764 & 0.130 & 0.230 \\
\hline Education (years) & 0.103 & 0.566 & 0.058 & 0.167 & 0.449 & 0.075 \\
\hline Residence (urban) & 0.078 & 0.851 & 0.066 & 0.064 & 0.708 & 0.046 \\
\hline Region & . & . & 0.021 & . & . & 0.022 \\
\hline Residual & . & & 0.186 & . & & 0.092 \\
\hline Total & . & . & 0.474 & . & . & 0.467 \\
\hline \multicolumn{7}{|l|}{ 9c. SBA } \\
\hline Age & -0.085 & -0.019 & 0.002 & -0.46 & -0.002 & 0.001 \\
\hline Child HH members & -0.33 & -0.023 & 0.008 & -0.476 & -0.037 & 0.018 \\
\hline HH size & 0.124 & -0.029 & -0.004 & -0.324 & 0.005 & -0.002 \\
\hline Wealth index & 1.278 & 0.095 & 0.122 & 2.3 & 0.125 & 0.287 \\
\hline Education (years) & 0.096 & 0.53 & 0.051 & 0.161 & 0.441 & 0.071 \\
\hline Residence (Urban) & 0.087 & 0.856 & 0.074 & 0.06 & 0.681 & 0.041 \\
\hline Region & . & . & 0.023 & . & . & 0.001 \\
\hline Residual & & . & 0.389 & . & . & 0.108 \\
\hline Total & . & . & 0.665 & . & . & 0.526 \\
\hline
\end{tabular}

Notes: Child HH members are household members under 5 years of age. HH size is total household size. The latest survey for ANC4+ and SBA is 2014. The latest survey used in this table for Contraceptive is 2011 . We used 2011 to add more family planning variables that were not included in the 2014 mini-DHS. Regions are dummies for each region with one reference region (Tigray) omitted from the regressions

coordinated action across the health, education, agriculture, and water sectors [20-22], it may take time to reduce the related inequality.

(3)Despite the narrowing trend, there is still substantial inequality in health services, especially in ANC4 and SBA. For example, in the 2014 survey, 35\% of the top $60 \%$ made four or more ANC visits compared to $11 \%$ of the poorer $40 \%$. Similarly, $24 \%$ of women from the top $60 \%$ of households had SBA, compared to just $5 \%$ of women from the bottom $40 \%$. In general, differences in favor of the rich (top 60\%) are large for most of the outcomes studied. The differences are even more pronounced between the poorest quintile (bottom 20\%) and the richest (top 20\%).
The correlations observed between household wealth and child health outcomes or $\mathrm{MNCH}$ service use are driven in part by such intermediate factors as women's education level and access to services like water and sanitation. However, the decomposition of inequalities found that even once these factors are accounted for, household wealth still has a direct effect on health service use and outcomes, and the changes in inequality observed are driven mainly by the direct effects rather than the intermediate factors [21, 22]. Increasing coverage of ANC4 and SBA goes beyond just making services available; there are also concerns about the quality of services (e.g., qualified staff, equipment, water and electricity for laboratories and delivery). The Government of Ethiopia has started taking action in this area, for example upgrading HEW qualifications so that they can be the 
equivalent of midwives. There have also been efforts to inventory facility readiness and address bottlenecks. Over the long term, a continuous quality improvement system could help to narrow the inequalities in health outcomes.

\section{Limitations}

How the DHS is designed affects how the indicators are constructed in ways that may affect the analysis of inequality. For example, because data on child vaccinations are collected as part of the women's questionnaire, they are only available for children whose biological mother is alive and in the household. Similarly, because infant and child mortality rates are calculated from information collected from women about all their births in the previous five years, it does not take into account deceased children whose mothers died giving birth or subsequently. In contrast, because data on height and weight were collected for all the children in the household, they should be fully representative.

In the analysis, we do see significantly worse nutrition outcomes for children whose biological mother is not alive or not in the household, suggesting that mortality rates may be underestimated and immunization rates overestimated. These biases would be worse for subgroups with higher rates of maternal mortality or (in the case of immunizations) fostering; if the biases are large, they may skew the inequality analysis.

Another limitation is that because data on ANC and SBA are collected in the women's questionnaire, they do not include pregnancies and births that ended in the death of mother. We would expect that poor antenatal or delivery care would be a risk factor for maternal mortality; we could be overestimating ANC and SBA, again with possibly differential biases based on the rates of maternal mortality in various subgroups.

\section{Conclusions}

Ethiopia's recent progress in $\mathrm{MNCH}$ was the starting point for fuller examination of the trends for rich and poor, and how wealth-related health inequality changed over the last two decades. The results obtained using various approaches led to similar conclusions: We found pro-rich inequality in certain health status outcomes but in general pro-poor progress in services. In addition, in both health status and services, there is still substantial wealth-related inequality. The decomposition exercise shows how certain socioeconomic status indicators, such as the wealth index and education, may help to explain existing inequalities. Ethiopia's efforts to improve access to health services have shown some positive results, but now it may be necessary, to change outcomes for the poorest, to focus on service quality and cross-sectoral interventions.

\section{Additional file}

Additional file 1: Table S1a. Detailed Definition of Indicators. Table S1b.Definition of Terms. (DOCX $58 \mathrm{~kb}$ )

\begin{abstract}
Abbreviations
ANC4+: Antenatal care, four or more visits; CPR: Contraceptive prevalence rate; DHS: Demographic and Health Survey; HEW: Health extension worker; IMR: Infant mortality rate; IUD: interauterine device; iup: intersection union principle (dominance test); mca: multiple comparison approach (dominance test); MDGs: Millennium Development Goals; MNCH: Maternal, newborn, and child health; NMR: Neonatal mortality rate; SBA: Skilled birth attendant; SDGs: Sustainable Development Goals; U5MR: Under-5 mortality rate; VCHW: Voluntary community health worker
\end{abstract}

\section{Acknowledgements}

We thank Anne Grant for editorial assistance. The views expressed in this paper are entirely those of the authors and do not represent those of the World Bank or any member country.

\section{Ethical approval and consent to participate}

The study used data from Demographic and Health Surveys (DHS) collected by the DHS program and Central Statistical Agency. Those who conducted the surveys reported that ethical considerations have been addressed. For the 2000, 2005, and 2011 surveys, please refer to the DHS program at: http:// dhsprogram.com/What-We-Do/Protecting-the-Privacy-of-DHS-SurveyRespondents.cfm. For the 2014 mini-DHS survey please see consents in the report: http://www.unicef.org/ethiopia/Mini_DHS_2014_Final_Report.pdf.

\section{Funding}

Not applicable.

\section{Availability of data and materials}

The study used four Demographic and Health Surveys, conducted in 2000, 2005, 2011, and 2014. The data from the first three surveys are available at https://dhsprogram.com. Data for 2014 were obtained from the Central Statistical Agency, Addis Ababa, Ethiopia.

\section{Authors' contributions}

AAA, CA, and QK conceived the research. AAA and EMF analyzed the data and drafted the report. AMB, CA, QK and HW reviewed and edited the draft report. AAA, EMF and HW revised the final document. All authors read and approved the final manuscript.

\section{Consent for publication}

Not applicable.

\section{Competing interests}

The authors declare that they have no competing interests.

\section{Publisher's Note}

Springer Nature remains neutral with regard to jurisdictional claims in published maps and institutional affiliations.

\section{Author details}

${ }^{1}$ The World Bank, 1818 H Street, Washington, DC 20046, USA. ${ }^{2}$ The World Bank, Addis Ababa, Ethiopia.

Received: 30 October 2016 Accepted: 14 August 2017 Published online: 22 August 2017

\section{References}

1. United Nations. Delivering as one in Ethiopia. Addis Ababa, Ethiopia, 2012. http://et.one.un.org/content/dam/unct/ethiopia/docs/UN\%20in\%20Ethiopia_ One\%20UN\%20Book\%20(3).pdf. Accessed 5 Apr 2017.

2. MDG Progress Index: Gauging country-level achievements. Center for Global Development (CGDEV), 2011 http://www.cgdev.org/page/mdg-progressindex-gauging-country-level-achievements. Accessed 31 Jan 2015. 
3. Central Statistical Agency [Ethiopia]. Ethiopia Mini Demographic and Health Survey 2014. Addis Ababa, Ethiopia. https://www.unicef.org/ethiopia/Mini_ DHS_2014_Final_Report.pdf. Accessed 20 Apr 2017.

4. Wagstaff A, Bredenkamp C, Buisman LR. Progress on global health goals: are the poor being left behind. World Bank Res Obs. 2014;29(2):137-62.

5. Onarheim KH, Tessema S, Johansson KA, Eide KT, Norheim OF, Miljeteig I. Prioritizing child health interventions in Ethiopia: modeling impact on child mortality, life expectancy and inequality in age at death. PLoS One. 2012; 7(8): 441521.

6. Wilunda C, Putoto G, Manenti F, Castiglioni M, Azzimonti G, Edessa W, Criel B. Measuring equity in utilization of emergency obstetric care at Wolisso Hospital in Oromiya, Ethiopia: a cross sectional study. Int J Equity Health. 2013;12:27.

7. World Bank. Health equity and financial protection datasheet: Ethiopia. Washington, DC: World Bank; 2012. http://documents.worldbank.org/ curated/en/942691468256149274/Health-equity-and-financial-protectiondatasheet-Ethiopia. Accessed 20 Apr 2017

8. Yesuf EA, Calderon-Margalit R. Disparities in the use of antenatal care service in Ethiopia over a period of fifteen years. BMC Pregnancy Childbirth. 2013;13:131.

9. Mirkuzie AH. Exploring inequities in skilled care at birth among migrant population in a metropolitan city, Addis Ababa, Ethiopia; a qualitative study. Int J Equity Health. 2014;13(1):110.

10. Rutstein SO, Rojas G. Guide to DHS statistics. Demographic and Health Surveys. Calverton, Maryland: ORC Macro; 2006. https://dhsprogram.com/ pubs/pdf/DHSG1/Guide_to_DHS_Statistics_290ct2012_DHSG1.pdf. Accessed 20 Apr 2017

11. Mckinnon B, Harper S, Kaufman J, Bergevin Y. Socioeconomic inequality in neonatal mortality in countries of low and middle income: a multicountry analysis. Lancet Glob Health. 2004;2(3):e165-73.

12. Moser K, Frost C, Leon DA. Comparing health inequalities across time and place raute ratios and rate differences lead to different conclusions: analysis of cross-sectional data from 22 countries 1991-2001. Int J Epidemiol. 2001; 36:1285-91.

13. Kakwani N, Wagstaff $A$, van Doorslaer E. Socioeconomic inequalities in health: measurement, computation and statistical inference. J Econ. 1997;77: 87-103.

14. Kjellsson G, Gerdtham UG. On correcting the concentration index for binary variables. J Health Econ. 2012;32:659-70.

15. O'Donnell O, van Doorslaer E, Wagstaff A, Lindelow M. Analyzing health equity using household survey data: a guide to techniques and their implementation. Washington, DC: World Bank; 2008.

16. Wagstaff $A$, van Doorslaer $E$, Watanabe N. On decomposing health sector inequalities, with an application to malnutrition inequalities in Vietnam. J Econometrics. 2003;112:207-23

17. Khan Q, Faguet JP, Ambel A. Blending top-down federalism with bottomup engagement to reduce inequality in Ethiopia. World Dev. 2017;96:32642.

18. World Bank Group. Ethiopia Poverty Assessment 2014. Washington, DC: World Bank. License: CC BY 3.0 IGO. 2016. https://openknowledge. worldbank.org/handle/10986/21323. Accessed 5 Apr 2017.

19. Wang H, Tesfaye R, Gandham NVR, Chekagn CT. Ethiopia health extension program: an institutionalized community approach for universal health coverage. Washington, DC: World Bank; 2016.

20. Ruel MT, Alderman H. Nutrition-sensitive interventions and programmes: how can they help to accelerate progress in improving maternal and child nutrition. Lancet. 2013;382(9891):536-51.

21. Amate-Fortes I, Guarnido-Rueda A, Molina-Morales A. Determinants of child health inequalities in developing countries: a new perspective. Soc. 2016;53: 641. doi:https://doi.org/10.1007/s12115-016-0072-y.

22. Marmot M. Achieving health equity: from root causes to fair outcomes. Lancet. 2007; 370:1153-63. doi: https://doi.org/10.1016/S01406736\%2807\%2961385-3.

\section{Submit your next manuscript to BioMed Central and we will help you at every step:}

- We accept pre-submission inquiries

- Our selector tool helps you to find the most relevant journal

- We provide round the clock customer support

- Convenient online submission

- Thorough peer review

- Inclusion in PubMed and all major indexing services

- Maximum visibility for your research

Submit your manuscript at www.biomedcentral.com/submit

) Biomed Central 